\title{
Las metáforas teatrales y el discurso de dignitas et miseria como fuentes de la mezcla jocoseria en El Criticón
}

\author{
Aurora GONZÁLEZ ROLDÁN \\ Universidad Nacional Autónoma de México
}

Los temas del discurso de dignitas et miseria hominis, presentes en toda la obra de Baltasar Gracián, se incorporan a El Criticón no sólo como parte del contenido o como simples yuxtaposiciones, sino que se integran a la ficción y a la particular poética de esta obra que muestra a dos luces el destino humano. Las miserias que según el discurso tradicional acosaban al hombre obtendrán una respuesta esperanzadora también construida, en parte, mediante la cantera de temas extraída del discurso de dignitas.

El libre albedrío del hombre digno actúa en un mundo semejante al escenario, entre los múltiples espacios teatrales que se van sucediendo en El Criticón. La facultad humana de contestar a su condición miserable se enlaza con la posibilidad de convertir la tragedia de la vida en una tragicomedia, con un final en la tierra más halagüeño que el que prometía la religión. Ambas tradiciones, entonces, pasan a formar parte de esta narración alegórica para mostrar el desdoblamiento de que es capaz el hombre, en la doble figura, gozosa y sufriente, que ejemplificaba el tópico de Heráclito y Demócrito.

PALABRAS ClAVE: dignitas et miseria, mezcla jocoseria, theatrum mundi, novela alegórica, sátira menipea.

The topics of the dignitas et miseria hominis tradition that emerge in all the works of Balthazar Gracián become a part of El Criticón not just as content or as simple juxtaposition, but integrated into the fiction and poetics of this account which shows human destiny under light and shadow. From the de dignitas tradition, in large part, Gracián built an answer to the miseries that beset humanity. The worthy man's free will performs in the world as on a stage, among a number of theatrum mundi that appear in El Criticón. Gracián's hero is able to answer to his own miserable situation, to change life's tragedy into tragicomedy and therefore to arrive to a better place at the end of his life on earth. Two traditions, thus, work in this allegory to show the double dimension of man, joyous and suffering, which exemplified the Heraclitus' and Democritus' topos.

KEY WORDS: dignitas et miseria, tragicomical mixture, theatrum mundi, allegorical novel, Menippean satire. 


\section{Dignitas et miseria hominis}

Al hablar de los tópicos del discurso de dignitas et miseria en la obra de Baltasar Gracián salta a la vista la privilegiada atención concedida a las excelencias del hombre en sus primeras obras, sobre todo en El Héroe y en El Político (Egido, 2001: 25), aunque los rasgos del varón eminente, sobre todo los relativos a las potencias del entendimiento, se encomian igualmente en la Agudeza y arte de ingenio y en el Oráculo manual (González Roldán, 2013a). Esta visión positiva del hombre y sus facultades intelectuales se extiende a El Criticón, donde no obstante se echa mano, por extenso, del discurso de miseria.

Puesto que se conoce la existencia de una doble visión, positiva y negativa, sobre distintas facetas del hombre en los tratados gracianos (Egido, 2001), también sería posible evocar un catálogo de miserias por defecto en El Héroe o en El Político, formado por todas aquellas características contrarias al ideal del príncipe o del varón heroico ahí vertidos, que más tarde se refleja en El Criticón, pues en el trayecto de los protagonistas encontraremos a cada paso el perfil del hombre que aspira a la inmortalidad por la vida recta y las obras relevantes, así como el vituperio de quienes, rehusando el esfuerzo, caminan hacia el vacío o a la "Cueva de la nada". En dichos tratados, así como en el Oráculo manual, se rechaza el comportamiento sujeto a las pasiones al igual que la negligencia en las acciones, pues el jesuita en muchos de sus aforismos concibe un vínculo entre la vileza y la ineficacia en las obras. Por otra parte, en el Oráculo manual concurren diversos elementos comunes a la metáfora del theatrum mundi y al discurso de dignitas et miseria, en aforismos que conciben al mundo y a la corte como un theatrum donde ha de lucir la sagacidad del prudente cortesano (González Roldán, 2013a). En suma, en el Oráculo parece proyectarse el ideal de un Heráclito piadoso, presente en los ideales de conducta de la época, que adquiere su prestigio gracias a la virtud y al control de los afectos, aunque en el caso de Gracián con ciertas precisiones y siempre desde una perspectiva alejada del ámbito religioso. ${ }^{1}$ Pero la síntesis y suma que Gracián realizó en el Oráculo recoge también los pasajes del Discreto, donde la excelencia del hombre incluye una perspectiva amplia y variada de un cortesano desenvuelto, admitiendo en ella el manejo controlado de actitudes jocosas y habilidades festivas.

La enorme repercusión del discurso de dignitas et miseria hominis en las tres partes de El Criticón se vincula con otros temas, como el de la dignificación por las letras, presente en todo momento en los tratados pedagógicos y, evidentemente, también en

\footnotetext{
${ }^{1}$ Con una obra como el Heráclito cristiano, Quevedo evoca la extendida presencia del tópico humanista que nos ocupa, en combinación con la devoción penitencial que acusa esta colección de poemas, ordenada a la manera de los cancioneros petrarquistas, en los que la cesura marcada por la renuncia al amor humano y la acogida del amor divino daba lugar a una abundante retórica de las lágrimas. Así, según avisa Lia Schwartz: "Los poemas de este ciclo, pues, combinan motivos y temas de la poesía moral de contexto neoestoico con otros característicos de la poesía religiosa" (Schwartz: XXV-XXIX).
} 
la obra de Gracián, a quien Erasmo y Vives ya habían abierto el camino en esa dirección, con la salvedad de que el jesuita siguió la vía secular también planteada durante el Renacimiento (Egido, 2001). No obstante, en El Criticón también repercute la apropiación que la tradición cristiana hizo de la oposición digna y miserable del hombre, con su realización más visible quizá en los autos sacramentales; no en balde el discurso de miseria hundía sus raíces en la tradición penitencial de la Edad Media, a partir de obras tan trascendentes como el De tristitia de Petrarca (Egido, 2001: 143-182). ${ }^{2}$

Gracián llevó a su obra prácticamente todos los tópicos de la dignidad del hombre unidos a las laudes litterarum, aunque sin restar importancia a los de la miseria, que emergen en El Criticón en múltiples ocasiones. En esta obra de ficción, el tema de la microcosmía, por ejemplo, se entrelaza —entre otros puntos en común- con los tratados sobre la dignitas, atendiendo aspectos centrales del tema como la búsqueda de la felicidad, el encomio del hombre como rector del universo o la aspiración a la inmortalidad en tanto que cualidad divina (Trinkaus: 356 ). ${ }^{3}$ Así, se destaca el relieve del espíritu renacentista que llega a El Criticón, pues no en balde los temas que actualmente se identifican en el discurso de la dignidad del hombre constituyeron las propuestas centrales del Renacimiento. Esta perspectiva nos permite identificar a Gracián como un continuador, por ejemplo, de las ideas de Pico della Mirandola en cuanto al tema de la libertad que ennoblece al hombre para poder hacerse a sí mismo según su propia voluntad, o en cuanto a la visión admirativa del ser humano (Egido, 2001: 147), aunque el jesuita introduciría no pocas innovaciones en éste y otros temas.

Obras como el De anima de Luis Vives, al igual que su Concordia y discordia en el linaje humano y la Fábula del hombre, o como el Diálogo de la dignidad y miseria del hombre de Fernán Pérez de Oliva, con la adenda de Francisco Cervantes de Salazar, habían dado continuidad a esta tradición en las letras españolas que Gracián retomaría pero en una trayectoria distinta, prescindiendo del marco religioso. ${ }^{4}$ Estos autores españoles atendieron de manera especial temas como la composición y anatomía del cuerpo humano, y las limitaciones y plenitudes que propician en las distintas edades del hombre, que serían fundamentales para la composición de El Criticón, pues se trata de un tema ampliamente aprovechado en contrastes y paradojas (Egido, 2001: 160). Ante este panorama, salta a la vista en la lectura de la Primera Parte de $\mathrm{El} \mathrm{Cri-}$ ticón que dignidad y miseria no son temas secundarios sino que constituyen una parte sustancial, implicándose en una larga serie de analogías y contrastes, pero con

\footnotetext{
${ }^{2}$ Para la relación de este tema con los autos sacramentales, en especial con Calderón, ver los trabajos de Eugenio Frutos (1951) y Alberto Gil (1982 y 1983).

${ }^{3}$ A. Egido indica que el concepto de felicidad que aparece en los tratados sobre la dignidad del hombre tiene una perspectiva cristiana, pero también estoica, que la identifica con la virtud y que condiciona el hilo narrativo de El Criticón (2001: 143-146). Habría que examinar con más detenimiento la componente estoica de la felicitas o summum bonum de estos libros y compararla con el que aparece en El Criticón, que sin duda mucho tiene de la filosofía del Pórtico.

${ }^{4}$ En esta última obra de Vives (153-162) es fundamental la metáfora del teatro del mundo que abordaremos en seguida.
} 
el claro objetivo poético de plantear la naturaleza tragicómica de la vida humana (Egido, 2001: 162-170).

Los abundantes elementos del discurso de miseria presentes en El Criticón se insertan no como digresiones doctrinales, sino que pasan a formar parte de los diálogos y en general de la ficción. En ellos podemos observar tanto la corriente humanista como la corriente teológica que señala Vega Ramos (2006). En las primeras crisis de la Primera Parte surgiría el ejercicio de la abjecto sui, fase culminante del proceso meditativo y penitencial que tenía como fin atacar el pecado de la soberbia. El De miseria de Inocencio III constituía una práctica de esta naturaleza que se trasluce en El Criticón, donde surge frecuentemente la oposición entre soberbia y humildad (Vega Ramos, 2003: 273). Se trata de una cuestión que el jesuita va a tratar con mayor enjundia en los volúmenes sucesivos, en relación con la honra (Segunda Parte, crisi IX, "El tejado de vidrio y momo tirando piedras") y la sabiduría (Tercera Parte, crisi XVII, "La hija sin padres en los desvanes del mundo"), en no pocas crisis. Al comparar El Criticón con las tres fases del tránsito por la vida del hombre que planteaba el De miseria, esto es, ingressus, progressus y egressus, se percibe en la obra del jesuita un paralelo con las dos primeras, aunque se trata de un progressus mucho más positivo, y además se traza un egressus que se sobrepone a las miserias. ${ }^{5}$

En cambio, en las primeras crisis de la Primera Parte, además del ingressus miserabilis, se incorporan los conocidos lugares de los libros de Plinio, el libro de Job o el Eclesiastés, entre otras fuentes veterotestamentarias, además de las clásicas (Vega Ramos, 2003: 273-276). El motivo del llanto infantil unido a las máximas consolatorias de Crántor y Cicerón, que acompañaban de manera tradicional los discursos sobre la llegada del hombre al mundo, también se verifican en esta obra. ${ }^{6}$ Ya Quevedo, entre tantos otros escritores que recogieron el tema, cotejaba mediante un concepto la desnudez y las lágrimas al principio de la vida: "Nací desnudo, y solos mis dos ojos / cubiertos los saqué, mas fue de llanto...” (Schwartz: 27). Y aunque Gracián no exhorta al llanto, a la manera de la tradición penitencial, éste conserva un rango moral que se coteja frecuentemente con el más bajo de la risa, y presenta al mundo como un lugar de penalidades, como se ve también en la narrativa de la peregrinatio vitae. ${ }^{7}$

\footnotetext{
${ }^{5}$ Sobre el desarrollo del discurso de dignitas et miseria, por extenso, en las tres partes de la obra de ficción graciana, me permito enviar a mi trabajo La paradoja de Heráclito y Demócrito en El Criticón, Prensas Universitarias de Zaragoza, en prensa.

${ }^{6}$ Como se sabe, las fuentes bíblicas son, en primer lugar, el libro de Job, III, 11; III, 20, y X, 18-19; además del Eclesiastés, IV, 2-3; VII, 2, y el libro de Jeremías XX, 14 y 17-18, entre otras. El "animal que llora" o flens animal aparece en Gracián como en Plinio (Nat. Hist, VII, I, 1-4) y en una gran cantidad de textos. Algunas de las más influyentes serían san Agustín, Inocencio III o Petrarca (Vega Ramos, 2003: 276). Vega Ramos (2009: 457-465) amplía la información sobre estas fuentes.

${ }^{7}$ Isaías XXXVIII, 59; Salmos XLI; Mateo XI, y Job V, IX, son algunas de las fuentes bíblicas que respaldaban la devoción penitencial del llanto en paralelo con la visión del mundo como un "valle de lágrimas", acrisoladas en la liturgia en torno al "gementes et flentes" del Salve Regina, que se hizo acompañar de una riquísima tradición musical.
} 
A lo largo de toda la aplicación que Gracián hace de los temas del discurso de dignitas et miseria, estaría haciendo una oposición constante de las doctrinas epicúreas y estoicas, pues va tejiendo en contrapunto miserias y excelencias. La antropología estoica aportaba, por ejemplo, el elogio de la creación y de las perfecciones del hombre, que se apoyaba principalmente en el De natura deorum y la literatura hexaemeral (Vega Ramos, 2003: 278 y 285). Gracián compartió la resolución humanista que se había decantado por la postura estoica cristiana rechazando en buena medida la visión negativa tanto de la tradición penitencial como del epicureísmo. Entre las excelencias así esgrimidas en la Primera Parte, encontramos el principio de la facultas imperandi o señorío del hombre sobre las criaturas (crisis II, III y VI); el principio teológico de la creatio propter hominem (crisi III) en términos no lejanos de los de Cicerón y de Lactancio; el elogio de la razón y las artes; la anatomía moral, cuyo modelo último parece residir en la obra ciceroniana y en los tratados de sexta die (crisi IX); el triunfo de la voluntad sobre el vicio (crisi X), o el de la razón y las letras (crisi XIII). ${ }^{8}$ Además, podemos advertir en el peregrinar de Andrenio y Critilo la facultad del libre albedrío, una característica única del hombre entre el resto de la creación que le confería dignidad al mismo tiempo que el riesgo de equivocarse, de manera similar al planteamiento vertido en La vida es sueño, de Calderón de la Barca, cuya impronta en El Criticón abordaremos enseguida.

Si Gracián insertaba las primeras crisis de su ficción en la tradición del patético ingressus del de miseria, se desligó por completo del egressus (Vega Ramos, 2003: 287). No parece tan interesado en mostrar a sus lectores los horrores de la muerte sino justamente lo contrario, plantear la posibilidad de alcanzar la dignidad cuando la edad avanzada impone las peores miserias. Gracián se aparta del catálogo de miserias de la tradición humanista, también de manera radical, al proponer la búsqueda de la inmortalidad por las letras al lado de la felicidad del sabio estoico. ${ }^{9}$ Además, en diversos lugares de su obra, valora la fama que conceden la historia o la filosofía moral, desdeñando la que buscaban los príncipes mediante sus retratos o mediante sus proyectos arquitectónicos.

\footnotetext{
${ }^{8}$ Vega Ramos (2003: 278) aporta numerosas referencias sobre el elogio de la mano, que aparece en la crisi XIX de la Primera Parte, además localiza en las sucesivas partes de El Criticón otros tópicos como el de la razón y las letras (crisis VI y X de la Segunda Parte), el del hombre acordado, hombre vihuela, y la correspondencia entre la música humana y la mundana (crisi II, Tercera Parte) y por tanto entre el micro y el macrocosmos; o el de la capacidad fabril del hombre (crisi VIII, Tercera Parte).

${ }^{9}$ Así, aunque la Tercera Parte de El Criticón pareciera conducir a una irremediable melancolía, la visión sobre el destino del hombre es positiva, como se deriva del cotejo que M. J. Vega Ramos ha realizado de esta obra con el discurso de miseria (2003: 290). Sin embargo, en cuanto a la inmortalidad por las letras cabe recordar que el Somniumscipionis de Macrobio o la Consolatio de Boecio despreciaban el prestigio literario y que el De remediis de Petrarca consideraba propio del vulgo la confianza en la fama literaria, equiparándola con la obtenida por la construcción de edificios.
} 


\subsection{Las metáforas del Theatrum mundi y el Mundo como teatro}

La prolífica metáfora del teatro del mundo, o de la vida como comedia, de la que han echado mano infinidad de autores desde la antigüedad, abarca no pocas perspectivas; más de una se enlaza con el difundido tópico de Heráclito y Demócrito que simbolizaron tanto las vertientes trágica y cómica del teatro, como el híbrido de la tragicomedia (Egido, 1997: 68-101). Esta metáfora es fundamental en La vida es sueño y El gran teatro del mundo de Calderón, cuyos puntos de contacto con el Theatrum mundi del moralista Boaistuau van más allá del título. Las primeras páginas de esta obra aluden explícitamente a los filósofos del llanto y la risa y destacan de la misma manera uno de sus vínculos con la perspectiva moral de las metáforas teatrales. ${ }^{10}$

En el Oráculo manual y las obras anteriores de Gracián, la doble figura de Heráclito y Demócrito se erige como símbolo de la sujeción de los afectos y de la disimulación. Para el jesuita, como para otros pensadores de influencia estoica, el individuo debería ser capaz de controlar y ocultar sus pasiones, de manera semejante a un actor competente, tal como enseñaba el célebre locus del Enquiridon de Epicteto (González Roldán, 2013a). En el Oráculo manual se despliega un amplio aprovechamiento de la metáfora del theatrum mundi que no sólo equiparó la vida con el teatro, sino que también trató cuestiones aledañas a la conservación y renuncia de una posición prestigiosa en la sociedad. Además, ya en El Discreto, Gracián contestaba a la tradicional metáfora que planteaba la vida como una ineludible tragedia, proponiendo sujetar las contingencias con el objetivo de lograr que los finales, tanto de la vida como de cualquier empresa, fueran igualmente felices. Gracián llevaba así un filón de la metáfora del teatro del mundo al ámbito de lo moral, alejándose de la dimensión piadosa al rechazar la actitud trágica, es decir, la que privilegiaban los textos edificantes, que concebían la vida como un valle de lágrimas, cuyo destino feliz se alcanzaba solamente en el cielo. El jesuita apostó más bien por un arte de vivir que fuera semejante a la tragicomedia y al ideal del hombre digno, es decir, que apelara a la facultad humana de transformar el destino propio gracias a los saberes y a la vida virtuosa. El final feliz de la tragicomedia de la vida sería una vejez fecunda y posiblemente la fama póstuma. Este planteamiento temporal, que Gracián propone en El Discreto, tendrá su mayor desarrollo en El Criticón, al mismo tiempo que los problemas relativos a la

\footnotetext{
10 "Algunos de los otros lloraron toda su vida la calamidad y miseria del hombre, no dando passo, ni mudandose de un lugar sin lagrimas, como Heraclito, persuadiendo siempre a todos que no era otra cosa esta vida sino un theatro de miserias y calamidades, que todo quanto se podía ver debaxo del cielo era un mar de passion digno de continuas lagrimas y sollozos. Otros, como Democrito, reyendo, burlando, y mofando hizieron cruda guerra a los vicios que reynauan en la tierra. El cual si agora resucitasse, y viesse la desorden y confusion de vicios, que ay en esta nuestra republica christiana, tenia mas justa causa de reyr, y mofar a vanderas desplegadas que jamas en sus tiempos tuvo" (1564: 10r-10v.). Christian Andrès señala que las traducciones al español de la obra del hugonote, publicada en 1558, comienzan en 1569, sin embargo, existen ejemplares — como la edición citada — de la traducción de Baltasar Pérez del Castillo publicados unos cuantos años antes (2004: 67-78).
} 
adecuada lectura y manejo de la esencia y la apariencia, aspecto atendido ampliamente en el Oráculo manual. Las falsas apariencias y el tema del mundo al revés son tópicos aledaños al theatrum mundi que igualmente serán desarrollados por extenso en todo El Criticón, estando ya patentes en la Primera Parte.

El camino que emprende el lector de El Criticón, junto a los dos protagonistas, se compone principalmente de una sucesión de espacios teatrales, donde Andrenio encuentra constantemente las maravillas que su joven discreción y su particular condición le llevan a admirar y a disfrutar, atribuyéndolas al Creador, como quería el celo religioso; pero además todos los espacios visitados son escenarios de aprendizaje, donde ambos protagonistas discurren y entablan diálogos sobre los portentos encontrados. Los diálogos, cargados de conceptos y de erudición, conllevan enseñanzas que proceden de una "conversión a lo moral" que aprovecha en gran medida las dificultades del estilo conceptuoso, que el lector puede seguir gracias a la escritura, pues se tiene así la posibilidad de hacer una lectura detenida o releer el texto a placer. ${ }^{11}$ Tanto los diálogos como la acción se hallan estrechamente relacionados con las estructuras de las crisis, estableciéndose una tupida red de enlaces entre los conceptos individuales y la estructura total de la obra, como correspondía a la agudeza compleja cabalmente lograda, según el ideal estético de Gracián.

En las últimas crisis de la Primera Parte se va a desarrollar por extenso otro tópico teatral, que incluye a un tiempo cuestiones escénicas y la equiparación de la vida con la comedia, aunque tratada de manera innovadora, nos referimos al tema de la casa de la Fortuna, que aparece flanqueada por dos puertas, una luminosa y otra sombría. Gracián utiliza este símil escénico, que aludía al arquetípico escenario de la comedia, para ejemplificar el peligro de confundir los fines con los medios, comparación que por otra parte ya había planteado Calderón en El gran teatro del mundo, aunque con mucho menor desarrollo. Pero el símil también resumía el programa general de El Criticón, pues planteaba la capacidad humana para dirigir el sentido de su paso por el mundo, ubicando en el justo lugar los medios y los fines, para salir de la vida por la puerta luminosa y no por la lúgubre. ${ }^{12}$

Ya la crítica se ha ocupado de comentar, al menos de manera inicial, la adopción que Gracián hace del tema del theatrum mundi en su obra de ficción, sobre todo aten-

\footnotetext{
${ }^{11}$ Lo anterior, que no ha pasado totalmente inadvertido por la crítica graciana, se deduce al considerar otras metáforas teatrales —además de la que equiparaba la vida a la comedia, con sus múltiples perspectivas - como las que expone Aurora Egido (1995: 87-196), sobre las cuales volveremos enseguida.

${ }^{12}$ Forastieri identifica la labor de desciframiento que los dos peregrinos van realizando a lo largo de todo El Criticón, con el paso por la casa de la Fortuna, pues ambos representarían el proceso del desengaño. Así cada signo develado ofrecería una primicia del encuentro con Felisinda. Sin embargo, consideramos que aunque efectivamente hay una relación entre tales elementos, el desengaño tiene además una función precisa, así como los actos de la voluntad, en la decisión final que toman los peregrinos y que posibilitan sus salidas por la puerta más conveniente, cada vez que se presenta el símil de la casa de la Fortuna, pues éste surge más de una vez y de manera distinta.
} 
diendo al deslinde entre realidad y la apariencia o el ser y el parecer. ${ }^{13}$ Antonio Vilanova mencionó brevemente la presencia del tema en El Criticón en su señero estudio sobre la metáfora del teatro del mundo, y más adelante Forastieri concluyó que la utilización de dicha metáfora no es más que una condición para que el individuo modélico realice una lectura desengañada del mundo que conduce a la felicidad, simbolizada en la búsqueda que realizan Andrenio y Critilo; objetivo con el que se ataría otro cabo de la metáfora, es decir, la obtención de un final de vida semejante al de la comedia. En efecto, es clara la utilización que Gracián hace de este símil, que ya se constata en la especial atención a los finales que pedía en los empleos del cortesano. Difiero, sin embargo, de la apreciación de Forastieri que identifica el final feliz de la comedia con el concepto de felicidad que buscan los peregrinos en El Criticón, simbolizado en Felisinda, pues creo que se trata de una categoría neoestoica y filosófica en general, que radica básicamente en el ejercicio de la virtud y el reconocimiento que de ello hace una comunidad, y por lo tanto es diferente del estado de felicidad psicológica comparable a la conclusión de la comedia. Aunque, en efecto, El Criticón utiliza de forma alegórica la felicidad del encuentro amoroso de la novela bizantina y buena parte de su estructura, muy posiblemente, refleja la de los autos sacramentales, es decir, de la comedia.

Sin duda, la repercusión de los símiles del theatrum mundi en El Criticón, además de plantear el problema de las esencias y las apariencias, alcanza mayores amplitudes. Por ello, creo que vale la pena revisar con mayor detenimiento algunos aspectos de la evolución de este tema, pues resulta pertinente compararlos directamente con el empleo que Gracián hizo de ellos.

Los textos de donde proceden las comparaciones más relevantes entre la vida humana y la comedia, según Vilanova, son las Epístolas a Lucilio de Séneca y el Enquiridion de Epictecto. ${ }^{14}$ De estos dos pensadores pasarían a Luciano y a Erasmo y a partir de sus obras se difundirían entre los escritores españoles, como Vives, además de las influencias más o menos directas de los dos primeros. Séneca compara la fugacidad de la vida con la de la comedia y equipara sus dos inevitables finales, la enseñanza asociada a esta idea invita a recordar lo ineludible de la muerte y a vivir de manera adecuada, representando con suficiencia el papel que ha sido asignado, sobreponiéndose a sus dificultades. En otro fragmento de sus Epistolas, Séneca establece una analogía entre las riquezas y dignidades de los hombres con el vestuario de los actores, concluyendo que ambos son sólo apariencias y que esconden una naturaleza diametralmente distinta; el final de la comedia, o sea la muerte, revela la igualdad de las personas que se esconden bajo las máscaras. Por otra parte, según el símil que

\footnotetext{
${ }^{13}$ Algunos trabajos que tocan el tema o al menos lo mencionan son los de Louise Fothergill-Payne (135), Pilar Gonzalbo (89), Emilio Hidalgo-Serna (197-214), Javier García Gibert (2004: 91, y 2002: 104-120), Emilia I. Deffis de Calvo (112) y Alfredo Aracil (197), entre otros.

14 “Quomodo fabula, sic vita; non Quamdiu, sed Quam bene actiasit, refert. Nihil ad rem pertinet, quo loco desinas. Quocumquevoles, desine: tantum bonamclausulam impone”, Epistolas a Lucilio (XX, IX, LXXVII, 20). Por otra parte, Forastieri (397), además de mencionar también las páginas de Curtius dedicadas al theatrum mundi, enumera no pocos estudios publicados hasta finales de los sesentas del siglo pasado.
} 
introduce Epicteto, Dios, como un autor de comedias, distribuye los distintos papeles entre los hombres, a quienes se confiere la tarea de ejecutarlo con pericia hasta el final de la representación (Vilanova: 153-157). Aunque como se sabe, existen también otras metáforas teatrales: en el Enquiridion, por ejemplo, precisamente la que hacía de Heráclito y Demócrito dos máscaras opuestas que simbolizaban la sujeción de los afectos, que el estoico debía ejecutar como si la vida fuese un escenario.

Una de las aportaciones más útiles del estudio de Vilanova para nuestro tema es el señalamiento de Luciano como un eslabón importante en la transmisión del tópico del theatrum mundi de los estoicos latinos a Erasmo, pues gracias al holandés llegaría a los españoles del XVI. ${ }^{15}$ El Gallo, El Ícaro y Menipo en los abismos son tres de los diálogos de Luciano donde aparece el tema. Además de los símiles ya mencionados, en dichas obras surge una tercera visión que mucho tiene que ver con $E l$ Criticón, esto es, la idea de un mundo semejante a un teatro donde reina la confusión creada por el vocerío de un gran número de diversos actores cuyas acciones son dignas de desprecio y de risa. Los tópicos del theatrum mundi en los diálogos de Luciano tendrían una repercusión enorme en la evolución de la sátira menipea, a la que se incorpora la obra que nos ocupa.

Entre las obras de Erasmo, el capítulo XXIX del Elogio de la locura que desarrolla algunas metáforas teatrales tendría una amplia repercusión en las letras españolas, en obras como el Examen de ingenios para las ciencias de Huarte de San Juan, donde al parecer tiene una influencia directa, o como el mismo Quijote, donde confluirían prácticamente todas las metáforas del theatrum mundi. Aunque Cervantes desarrollaría mucho más que los textos anteriores la idea de la realidad aparente que la comedia de la vida ofrece a los ojos del espectador. El Guzmán de Alfarache, que recogió estas metáforas, introduciendo también la acción de la Fortuna, es otro de los textos fundamentales en la tradición, así como la traducción y comentarios que Sánchez de las Brozas hiciera del Enchiridión de Epicteto (Vilanova, 1950). Más adelante, la reelaboración más apreciable del tema del teatro del mundo después de las obras Calderón sería justamente El Criticón. ${ }^{16}$ La relevancia de estas consideraciones se justifica en toda amplitud si tomamos en cuenta la estrecha relación del Elogio de la locura con la crisi VII de la Primera Parte de El Criticón, a propósito de este lugar común (González Roldán, 2013 b) ${ }^{17}$

Las reelaboraciones de las alegorías tradicionales de la Fortuna, que son recurrentes en los tres tomos de El Criticón, alcanzan ya en la Primera Parte más de una manifes-

\footnotetext{
${ }^{15}$ Entre otras obras, Vilanova menciona al Crotalón de Christophoro Gnosopho, la Diana Enamorada de Gaspar Gil Polo, o la Comedia Intitulada Doleria del Sueño del Mundo, de Pedro Hurtado de la Vera.

${ }^{16}$ Un sermón de Pedro de Valderrama y "El teatro scénico a los hombres" de la Nueva idea de la tragedia antigua de González de Salas, serían textos muy cercanos a Calderón, según H. G. Jones (51-60).

${ }^{17}$ Cabe recordar que la metáfora de la vida como comedia también había surgido en la Fabula adhomine de Juan Luis Vives, en la Institutio de Calvino, en san Agustín y en san Juan Crisóstomo. Jacquot (1957) señala que san Juan Crisóstomo unió por vez primera las metáforas de la vida como comedia y como sueño (apud. Domingo Ynduráin: XXVIII).
} 
tación: las encontraremos de manera puntual en las crisis IV y XI, pero además el tema llega a permear prácticamente todo el libro, con las continuas alusiones a los temas náuticos, pues comienza con el naufragio de Critilo y termina encomiando a la Odisea como la guía por excelencia del hombre en la corte, en imitación del sagaz Ulises ( $I b$.).

La relación entre el teatro y la Primera Parte de El Criticón quedaba clara al lector ya al abrir el libro, pues no en balde Gracián hacía en los epígrafes de las crisis claros guiños a los autos sacramentales, a los calderonianos y a otros anteriores, al enmarcar su libro entre "El maravilloso teatro del mundo" y "La feria de todo el mundo". Esta última evocaba autos sacramentales como El gran mercado del mundo de Calderón o Las ferias del alma de Francisco de Valdivielso. Sobre la primera de ellas señalaba Valbuena Prat, de manera breve: "Hay en este auto una concepción filosófica de la vida, conforme con nuestra tradición senequista. Dos son sus principales puntos que podemos llamar: la gran feria de la vida, y la posada del mundo. Del primero hay en la literatura contemporánea de Calderón una excelente muestra en el Criticón de Gracián" (Primera Parte, crisi XIII): "La feria de todo el mundo" (Valbuena Prat, 1952: 224).

Valbuena menciona además, en relación con el realismo de los autos calderonianos, una obra como el Mesón del mundo de Rodrigo Fernández de Ribera (1632), que, según nos dice, pudo fundamentarse en el auto anterior de Calderón, y que es de factura conceptista. Ana Suárez, en su edición del Gran mercado del mundo, menciona, también de manera rápida, el motivo del mercado en la crisi XIII de la Primera Parte. La crisi titulada "La feria de todo el mundo" muestra el compendio que Gracián hace de una tradición que pasa por Prudencio, Séneca, San Ambrosio, los exempla y los emblemas (2002: 148-152). ${ }^{18}$

Aunque la similitud entre los epígrafes de las crisis y los autos puede atribuirse también a la factura alegórica y los temas compartidos con los autos, no era difícil que el lector vinculara igualmente la crisi XII, "Los encantos de Falsirena", con Los encantos de la culpa, o la crisi XI "El golfo cortesano", con El golfo de las sirenas, pues el recuerdo de estas obras estaría reciente en la memoria de los espectadores cuando aparece la Primera Parte de El Criticón. ${ }^{19}$ En todo caso se trataba de un gusto y aprecio por la alegoría que continuaba vigente en los lectores y espectadores de la segunda mitad del siglo XVII.

En general, la dimensión teatral de El Criticón atañe no sólo a los contenidos sino a su forma, concebida como un complejo teatro de la memoria (Egido, 1986). Por ello, una comparación por extenso entre El Criticón y el teatro, en especial atendiendo a los autos sacramentales, parece ser tarea pendiente. Este último es un género fundamental para la Primera Parte, no por simple yuxtaposición como había hecho Lope de Vega,

\footnotetext{
${ }^{18}$ En mi estudio sobre la emblemática en El Criticón, me ocupo de la repercusión de este género en relación con las metáforas de las escenificaciones y personificaciones del mundo (2013b).

${ }^{19}$ Aunque la zarzuela mencionada, El golfo de las sirenas, se representó unos años más tarde, en 1657. Se ha fechado la composición de El gran mercado del mundo alrededor de 1635, pero su primera representación en Madrid fue en 1649; Los encantos de la culpa se estrenaría entre 1645 y 1647 (Egido, 1982).
} 
también en el marco de la novela bizantina, pues Gracián traslada elementos temáticos y formales de la escena alegórica a la estructura de la narración. ${ }^{20}$

Gracián y Calderón, así como Lope y otras grandes figuras del Barroco, se habían formado en colegios jesuitas y poseían en su bagaje cultural las enseñanzas del teatro escolar y la experiencia de haber asistido a sus puestas en escena, a un tiempo didácticas y fastuosas. Los jesuitas habían intentado adaptar, en su teatro, la herencia del teatro clásico, en especial de Terencio, con una finalidad didáctica que atendiera tanto a la formación intelectual como ética (Menéndez Peláez: 33-76). ${ }^{21}$ La fuerte presencia de esta finalidad moralizante separaba al teatro jesuítico del teatro universitario, aunque ambos vertían en el cauce dramático los presupuestos de la retórica sacra, haciendo del teatro un nuevo púlpito. Tiempo después Calderón repararía en las similares funciones del auto sacramental y del sermón. ${ }^{22}$ Así, podemos constatar que la risa y el llanto ya se mezclaban en el teatro jesuítico, pues al parecer la conmoción afectiva que provocaban los sermones era comparable al de las puestas en escena que también mezclaban lo serio y lo risible. ${ }^{23}$ Como se sabe, los sermones contenían además de la finalidad moralizante, las herramientas que la retórica clásica había enseñado en cuanto al uso de los teatros de la memoria. Sin contar con las técnicas de meditación promovidas por Ignacio de Loyola, cuya práctica incluía el examen general de conciencia, la confesión frecuente y el pensamiento permanente en la muerte. Aunque la actitud ante la muerte del pensamiento graciano iba a dar testimonio de grandes cambios.

Otro de los elementos que, al parecer, pasan del teatro jesuítico a los autos sacramentales es la fastuosidad de la escenografía, y éste sería el principal punto de encuentro entre el teatro jesuítico y los autos de Calderón. Hay testimonios del interés que los jesuitas ponían en la magnificencia de la escenografía y el vestuario que se utilizaba en las representaciones, en ambos lados del Atlántico, que era capaz de atraer

\footnotetext{
${ }^{20}$ Egido (2005), por su parte, señala que la antigua idea de la peregrinación fue común al auto sacramental y a la novela. Deffis de Calvo advierte también la función de los autos sacramentales insertados por Lope en El peregrino en su patria, pero no abunda demasiado en cuanto a su utilización en El Criticón (59-61 y 112).

${ }^{21}$ Según Menéndez Peláez, a pesar de que entre los jesuitas prevalecía el rechazo del teatro clásico, en especial las comedias de Terencio — pues las habían repudiado también san Gregorio Magno, san Juan de Ávila y el mismo san Ignacio, entre otros-, están presentes en el teatro jesuítico, junto con las de Plauto, pues además de su temprana cristianización, la Ratio studiorum de 1586 permite la enseñanza del latín por medio de tales autores.

${ }^{22}$ J. Menéndez Peláez recoge la observación de Astrain sobre el teatro de Acevedo: "trocó los teatros en púlpitos, y salían los hombres muchas veces más recogidos y llorosos de sus presentaciones que de los sermones de algunos excelentes predicadores" (44 y 68).

23 "Por tanto, los estudiantes / de Jesús y de San Gil / traen una cosa vil / y propia de principiantes [...] / es un sermón disfrazado; / hablan burlando y de veras; / entre cosas placenteras / el provecho irá mezclando" (46). Según Menéndez Peláez (48-50) son de relevancia las relaciones entre el arte de la predicación y el teatro de los siglos de oro, señala que las "instrucciones de predicadores" eran auténticos manuales para los actores y que la estructura que suelen utilizar los dramaturgos refleja la del sermón: presentación, desarrollo y colofón. La primera parte solía escribirse en castellano, para la mejor comprensión de la obra, escrita en latín. Con respecto a la "dispositio externa", señala Menéndez, entre otros elementos, la intercalación de breves piezas jocosas que luego darían origen a la loa y al entremés.
} 
con fruición al público. Los elementos visuales tendrían una buena acogida entre los asistentes que sin saber latín podían seguir el argumento a partir del prólogo recitado en castellano (Menéndez Peláez: 52-67). Al parecer, algunos de los rasgos más relevantes en el teatro jesuita son la creación de espacios, la perspectiva, la riqueza de los trajes y la traslación de ideas abstractas o contenidos doctrinales a formas plásticas sensibles $(60) .^{24}$

Justamente son relativos a la escenografía los elementos de El gran teatro del mundo de Calderón que Gracián recoge y celebra en la Primera Parte de El Criticón de manera relevante, aunque también trasladó otros elementos del espacio escénico, personajes y mecanismos de los autos sacramentales. Nos referimos a la idea del mundo como teatro que Calderón desarrolla por extenso en sus autos y que constituye un núcleo un tanto diferente de las metáforas del theatrum mundi que mostraban a la vida como una comedia. En dicho auto, como en tantos otros de Calderón, el Mundo surge como personificación alegórica y como espacio cósmico respondiendo a una larga tradición teológica y literaria. ${ }^{25}$ Las múltiples advocaciones que adquiría el mundo, como espacio escénico en los autos sacramentales, ya sea cosmos, plaza, posada, laberinto, prisión o mercado pasan a ser, en El Criticón, los escenarios donde tienen lugar las acciones de Andrenio y Critilo. ${ }^{26}$

En El Criticón los espacios imaginarios corresponden a la poética de la alegoría, y son comunes también a la sátira menipea. Por otra parte, el anclaje en el mapa europeo real, que se afianza en ocasiones puntuales pero que nunca se abandona, respondería a la tradición de la novela griega y de la peregrinación a Roma, que se enlaza con la perspectiva topográfica ya presente en los autos de Calderón. ${ }^{27}$ De esta manera, gracias a la mezcla de géneros, los ricos decorados del teatro barroco que evocaban la armoniosa belleza del universo se convertían en El Criticón en la naturaleza misma, pues en las primeras crisis no aparece ningún personaje alegórico, sino que se introduce al lector en la contemplación del universo, para seguir luego por espacios casi siempre alegóricos o imaginarios, con las señaladas breves conexiones con la topografía real.

${ }^{24}$ El autor sigue en este punto a Florencio Segura (1982).

${ }^{25}$ Así puede resumirse el largo recorrido que la idea del teatro del mundo tiene en los autos sacramentales de Calderón, como ha mostrado Aurora Egido (1995: 3-36). La autora recoge el trabajo de Eugenio Frutos (1981), donde estudió el mundo como tema moral, atendiendo a su caracterización escénica y el concepto de macrocosmos, así como el de Otis H. Green, centrado en el tema del mundo en las letras hispánicas, además de trabajos afines como los de Spitzer, Lewis, Wilson y Allen, entre otros

${ }^{26}$ A partir de El gran teatro del mundo y de El gran mercado del mundo aparece como personificación presidiendo plazas, posadas y teatros. Siendo amplia la gama de espacios arquitectónicos de Mundo: la nave y el mar a la posada, la cárcel, el palacio, el laberinto y el camino (Egido, 1995: 4).

${ }^{27}$ Egido (1995: 6) recuerda que la observación de la naturaleza como camino para llegar a Dios era una idea agustiniana que se difundió en numerosos tratados y polianteas. Spitzer separa a Calderón de san Agustín para acercarlo a san Ambrosio en este aspecto, y envía al estudio de Bruyne (1963). Por ello, en una obra como el Persiles, entre tantas otras, se plasma la idea de la peregrinatio vitae, con fundamento geográfico tomado de Plinio, Ptolomeo, Estrabón, Torquemada, Mexía y Tamara, entre otras fuentes (Egido, 1995: 11) 
En la Primera Parte de El Criticón salta a la vista la concepción de los espacios como teatros, según indicaba la misma etimología. ${ }^{28}$ De esta manera, se pone ante la vista del lector la vía de aprendizaje de los peregrinos, donde la lectura perspicaz del entorno es la lección de oro. Además, la tradición de la idea del mundo como imagen de dios o la del mundo como libro, que repercute de manera relevante en El Criticón, estaban presentes también en el teatro de Calderón. ${ }^{29}$

La teatralización que persiste en todo El Criticón también echó mano del recurso del teatro en el teatro, como lo había utilizado Calderón en varias de sus obras. ${ }^{30} \mathrm{La}$ inserción de este mecanismo alcanza en la crisi VI la realización más relevante de la Primera Parte (González Roldán, 2013b). Para Domingo Ynduráin, la metáfora del mundo como teatro tiene dos posibles consecuencias; la primera de ellas, a la que se adscribiría el auto de Calderón, concibe simplemente al mundo como un teatro donde se representa la vida humana, la realidad coincide con la representación teatral, sin escisión ni conflicto entre ambas, no se anulan sino que se apoyan mutuamente. Por otra parte, de acuerdo con una segunda significación, que aparece en otras obras, como El Criticón, la metáfora implica una contradicción entre ser y parecer, entre figura y figurería. ${ }^{31}$ Parece evidente que en El Criticón ha tenido mayor repercusión la segunda significación, sin embargo, la primera de ellas también está contemplada en la factura de la obra, pues ya la crisi I, título incluido, no deja lugar a duda de que se está recogiendo la idea del mundo como escenario de la comedia de la vida.

Pero quizá una de las repercusiones más trascendentes de los autos sacramentales o la comedia jesuítica, con sus metáforas continuadas, en El Criticón sería la mencionada adopción de la comedia o la tragicomedia a manera de estructura global (Egido, 2009: CXLIII). ${ }^{32}$ Gracián adoptaba así, a discreción, recursos del teatro, en el fondo y la forma de su narración, pero atendiendo a una perspectiva filosófica

${ }^{28}$ A. Egido recoge las observaciones de Amedeo Quondam (1980) sobre el significado de la sentencia "teatro del mondo" que equivalía a los loci de la memoria donde se depositaban los saberes (op. cit.: 13), una acepción que también refiere Domingo Ynduráin (1977).

${ }^{29}$ Para ambos autores sería fundamental un texto como la Introducción al símbolo de la fe de fray Luis de Granada, que se inscribe en la tradición de la lectura del mundo.

${ }^{30}$ Así lo advierte A. Egido en su estudio preliminar a la edición facsímil de El Criticón. Primera Parte (Baltasar Gracián, 2009: CLXXVIII).

31 "La contradicción se expone, formalmente, de manera crítica: las dos facetas de la realidad son analizadas y enfrentadas entre sí, careadas hasta llegar a la desrealización y destrucción de una de ellas" (Ynduráin, 1997: LIV). En cuanto a la primera significación, Ynduráin agrega: "no hay lugar para la crítica que analiza el comportamiento doble del hombre y que sitúa la contradicción en el plano social, circunstanciando las actuaciones" (idem.).

${ }^{32} \mathrm{Al}$ respecto conviene tener en cuenta que para la época de Lope el auto sacramental ya había asimilado la forma de la comedia, presentando frecuentemente la división del acto único en tres partes, agrupación binaria de personajes (dama-galán, gracioso-criada), según explica Ynduráin. Además, el estudioso recoge la observación de Flekniacoska sobre la codificación del vestuario: "Caridad, Iglesia van vestidas de damas; Fe, Envidia y Soberbia, de gitanas; Engaño, Entendimiento y Memoria, de viejos con barba y cabello blanco; Avaricia, de turco; Cristo y Rigor, de caballeros; Honor, Amor de Dios y Apetito, de adolescentes, sin hablar de todos los que llevan vestidos de pastores o villanos” (1997: XXXI-XXXII). 
moral que aprovechaba el didactismo de aquellos géneros pero sin incorporar su perspectiva religiosa.

Como es sabido, El Criticón se desligó casi por completo de los discursos de carácter piadoso, sin embargo, realizó una función, por medio de la narrativa análoga a la que del auto sacramental: difundir complejos planteamientos entre un público amplio, en virtud de la utilización de la alegoría. ${ }^{33}$

Egido llama la atención sobre el brillante papel que jugaron las alegorías en los festejos de la fundación del Colegio Imperial de Madrid, en 1640, y la consagración de su templo, en 1651. Señala las posibles relaciones de El Criticón con Las glorias del mejor siglo, en cuanto al uso de las personificaciones alegóricas, y con Obrar es durar, en cuestiones estilísticas, pues ambas obras fueron representadas durante aquellos festejos a los que posiblemente asistió Gracián. En esta última obra, con escenografía de Cosme Lotti, intervienen alegorías similares a las que luego surgen en el relato alegórico $(\mathrm{XXX}){ }^{34}$

Teniendo en cuenta la repercusión del teatro jesuita y de los autos sacramentales en El Criticón es inevitable establecer un paralelo entre los numerosos personajes alegóricos que intervienen, al igual que los espacios escénicos donde se desarrolla la acción. ${ }^{35}$ Aunque en esta obra las personificaciones se presentan de manera sucesiva, a diferencia del auto sacramental, que frecuentemente los reunía en escena. ${ }^{36}$ Igualmente, salta a la vista una división entre los personajes que habitan de manera permanente los espacios visitados y los guías que, a tramos, acompañan el peregrinaje de nuestros protagonistas. Con ambos tipos de personajes se entablan diálogos de observación y análisis del entorno - con algunas excepciones, por ejemplo cuando los guías aparecen muy brevemente- y cuyas acciones se infieren ya de su misma caracterización. Por otra parte, son escasas las batallas espirituales o materiales entre las alegorías maléficas y

${ }^{33}$ Ésta sería otra característica que permite enlazar a El Criticón con la comedia (Egido, 2009: CXLII). Valbuena Prat menciona también la difusión o democratización doctrinal que efectuaban los autos de Calderón.

${ }^{34}$ En Las glorias del mejor siglo, nos dice la autora, aparecen la Discreción, el Gracejo y el Gusto, así como las cuatro partes del mundo.

${ }^{35}$ En las obras colegiales jesuíticas también habían sido numerosos los personajes, para propiciar el máximo posible de ejercicios retóricos en apoyo del aprendizaje de la lengua latina (Menéndez Peláez: 64). El autor también hace referencia a las relaciones de las grandes fiestas jesuitas en Madrid de 1640 y 1651 , además de otras como las realizadas con motivo de la canonización de Ignacio de Loyola, Teresa de Jesús, Francisco Javier e Isidro Labrador, en 1622, y por lo tanto anteriores a la llegada de Cosme Lotti. Subraya el desfile, realizado el 6 de mayo, que abrieron un centenar de niños tan profusamente ornamentados con joyas y piezas de valor que fue necesario hacerlos acompañar por un escuadrón de la guardia real, sin mencionar el resto del cortejo que incluía carrozas representativas de los cuatro continentes, así como del sol, la luna y otros elementos naturales (59-60).

${ }^{36} \mathrm{Sin}$ embargo, algunas veces aparecen grupos de personajes reales imaginarios en El Criticón, como los descritos en la crisi VI, pues al parecer la enumeración de tipos sociales o morales de estos conjuntos sería un rasgo de la sátira medieval que habría pasado a la sátira menipea de la Edad Moderna (González Roldán, 2013b). Los tipos satíricos de la crisi VI son secundarios, en comparación con otras figuras alegóricas y satíricas como el dios Momo que interviene en la Segunda Parte o el soldado de la última crisi de la Tercera Parte. 
las benéficas, tan usuales en los autos, quedando siempre la acción de la historia supeditada a la elección y decisión o acción de los protagonistas, quienes siguen los trazos de la filosofía graciana. De esta manera, la acción alegórica se desarrolla en mayor medida mediante la peregrinación, según la diferenciación entre los dos tipos de alegoría que establece Fletcher (147-178), quedando la batalla interior en segundo plano.

Finalmente, me interesa destacar que en los autos de Calderón se distinguen, además de las dos dimensiones del Mundo, como personaje y como arquitectura, dos valoraciones desde el punto de vista teológico: la que consideraba al mundo como una entidad neutra compuesta por la suma de lo visible y lo material, y la que advertía sobre los peligros y los engaños que comportaba. Por lo tanto, las alegorías que presiden de manera estable los espacios visitados por Andrenio y Critilo pueden ser vistos como equivalencias del Mundo, como personaje alegórico de los autos sacramentales, pues al igual que éste exhiben los atributos relativos a sus territorios y poderes y pueden ser moralmente adversos o benéficos. De manera similar, en las alegorías de los guías podríamos ver un paralelo del Mundo como personaje que, invistiendo al "autor de comedias" o incluso al poeta, hace avanzar la acción dramática. ${ }^{37}$ De manera similar, las tríadas compuestas por Andrenio, Critilo y el guía de turno hacen las veces del Mundo que, convertido en el "vulgo" de la comedia, contempla la escenografía o la acción del auto. ${ }^{38} \mathrm{Se}$ trata, sin embargo, en este caso de un público activo que emprende continuamente un debate sobre lo observado, a la manera de los diálogos renacentistas.

\section{Obras citadas}

ANDRÈs, Christian. 2004. "La metáfora del "Theatrum mundi" en Boaistuau y Calderón (en La vida es sueño y El gran teatro del mundo)". Criticón, núm. 91. Toulouse: Université de Toulouse II / Le Mirail. Pp. 67-78.

AraCIL, Alfredo. 1998. "El engaño de los sentidos en Gracián, Bacon, Campanella" y "Juego, teatro, laberintos". Juego y artificio: autómatas y otras ficciones en la cultura del Renacimiento a la Ilustración. Madrid: Cátedra.

${ }^{37}$ A. Egido advierte que el "autor de comedias" valía tanto como escenógrafo y tramoyero de Dios (1982: 18). Y agrega: "En otras ocasiones es su voz la que convoca y presenta a los demás personajes, hace avanzar la acción, o impulsa cambios escenográficos... su palabra sirve en ocasiones de acotación escénica, acompañando las mutaciones o creando en el espacio de la representación la memoria misma de las apariencias [...] llegando incluso a tomar el papel del poeta, como en El indulto general" (28). Domingo Ynduráin llama la atención sobre la investidura de Mundo, como personaje o bien como espectador del auto, al analizar la disposición de los carros esféricos en la representación de El gran teatro del mundo, lo que se comprueba fácilmente en los versos 659-674, donde el Mundo se declara a sí mismo espectador o "vulgo", pues la Ley de Gracia toma la delantera introduciendo indicaciones.

${ }^{38}$ A. Egido (1982) habla de dos funciones, una interrogativa, con numerosos ejemplos, y otra admirativa (¿Quién hallará mujer fuerte?); así como de las funciones explicativa y catequética, pues la riqueza de la entidad del Mundo hace que sea muy versátil como personaje, siendo escenógrafo, autor de comedias, apuntador y espectador, además de personaje propiamente dicho. 
Boaistuau, Pierre. 1564. Theatro del mundo. Alcalá: Casa de Andrés Angulo.

BruYNe, Edgar de. 1963. Historia de la estética. Madrid: Biblioteca de Autores Cristianos.

CAlderón de la BARCA, Pedro. 1952. Obras completas. Autos sacramentales, III. Ed. A. Valbuena Prat. Madrid: Aguilar.

DefFIS DE CALVo, Emilia I., 1999. Viajeros, peregrinos y enamorados. La novela española de peregrinación del siglo XVII. Pamplona: EUNSA.

EGIDO, Aurora. 2005. En el camino de Roma. Cervantes y Gracián ante la novela bizantina. Zaragoza: Universidad de Zaragoza.

2001. "Dignidad y miseria del hombre en El Criticón". Humanidades y dignidad del hombre en Baltasar Gracián. Salamanca: Ediciones Universidad Salamanca.

1997. "Heráclito y Demócrito. Imágenes de la mezcla tragicómica". Teatro del Siglo de Oro: teoría y práctica. Ed. Christoph StroseTZKi. Madrid / Fráncfort: Vervuert. Pp. 68-101.

1995. "El Mundo". El gran teatro de Calderón: personajes, temas, escenografia. Kassel: Reichenberger. Pp. 87-196.

. 1986. "Las artes de la memoria y El Criticón”. Gracián y su época. Zaragoza: Institución Fernando el Católico.

1982. La fábrica de un auto sacramental. "Los encantos de la Culpa". Salamanca: Universidad de Salamanca.

Fletcher, Agnus. 2002. Alegoría: teoría de un modo simbólico. Madrid: Akal.

FORASTIERI BRASCHI, Eduardo. 1977. "Baltasar Gracián y el Theatrum mundi". Actas del V Congreso de la Asociación Internacional de Hispanistas. Ed. François Lopez et al. Burdeos: Université de Bordeaux.

FOTHERGILL-PAYNe, Louise. 1977. La alegoría en los autos y farsas anteriores a Calderón. Londres: Tamesis Books Limited.

Frutos, Eugenio. 1951. "Dignidad y miseria del hombre". La filosofía del Barroco y el pensamiento de Calderón. Buenos Aires: Universidad de Buenos Aires. Pp. 178-181.

GARÍA, Javier. 2004. "El ficcionalismo barroco en Baltasar Gracián”. Gracián: Barroco y modernidad. Eds. Miguel GRANDE YÁÑEZ y Ricardo PINILLA. Madrid: Universidad Pontificia Comillas / Institución Fernando El Católico / Diputación de Aragón.

2002. Baltasar Gracián. Madrid: Síntesis.

GIL, Alberto. 1983. "La antropología en Calderón: elementos válidos y actuales del hombre en su teatro". Hacia Calderón. Sexto Coloquio Anglogermano (Würzburg, 1981). Ed. Hans Flasche. Wiesbaden: Franz Steiner. Pp. 123-133. 1982. "La dignidad de la persona humana en el auto sacramental La vida es sueño". Persona y Derecho: Revista de Fundamentación de las Instituciones Jurídicas y de Derechos Humanos, núm. 9. Pp. 225-238. 
GonZalbo, Pilar. 1989. La educación popular de los jesuitas. México: Universidad Iberoamericana.

GonZÁlez Roldán, Aurora. [2013a]. Risa y llanto en los tratados de Baltasar Gracián: de El Héroe a la Agudeza y arte de ingenio. Valladolid: Secretariado de Publicaciones de la Universidad de Valladolid [en prensa].

. [2013b]. La paradoja de Heráclito y Demócrito en El Criticón. Zaragoza: Prensas Universitarias de Zaragoza [en prensa].

Gracián, Baltasar. 2009. El Criticón. Primera Parte. Edición facsimilar. Estudio introductorio Aurora EGIDO. Zaragoza: Institución Fernando el Católico / Gobierno de Aragón.

HidALGO-SERNA, Emilio. 1993."La lógica del ingenio en un monólogo de La vida es sueño". El pensamiento ingenioso en Baltasar Gracián: el "concepto" y su función lógica. Barcelona: Anthropos. Pp. 197-214.

JACQUOT, Jean. 1957. "Le 'Thèâtre du monde' de Shakespeare à Calderón". Revue de littérature comparée, XXXI. París: Didier Érudition. Pp. 341-372.

Jones, H. G. 1997. "Calderón's El gran teatro del mundo: Two Posible Sources", Journal of Hispanic Philology, I (1976-1977). Tallahassee: Journal of Hispanic Philology. Pp. 51-60.

MenÉndeZ PeláeZ, Jesús. 2001. "El teatro jesuítico: sistemas y técnicas escénicas". Calderón, sistema dramático y técnicas escénicas: Actas de las XXIII Jornadas de Teatro Clásico, Almagro, 11, 12 y 13 de Julio de 2000. Coord. Felipe B. PEDRAZA JimÉnEZ. Almagro: Universidad de Castilla-La Mancha.

Quondam, Amedeo. 1980. Il teatro del Rinascimento. Ed. Maristella de PANIZZA Lorch. Milano: Ed. di Comunità.

SChwarTZ, Lia. 1998. "Estudio preliminar", Francisco de Quevedo: Un Heráclito cristiano, Canta sola a Lisi y otros poemas. Barcelona: Crítica.

SEgura, Florencio. 1982. "Calderón y la escenografía de los jesuitas". Razón y Fe, núm. 205. Madrid: Razón y Fe. Pp. 15-32.

SuÁREZ, Ana. 2002. "La alegoría del mercado en Gracián: resumen de una época". El gran mercado del mundo. Pamplona / Kassel: Ediciones Richenberger / Universidad de Navarra. Pp. 148-152.

TrinKAUS, Charles. 1983. The Scope of Renaissance Humanisme. Anne Harbor: University of Michigan Press.

VEGA Ramos, María José. 2009. "El animal que llora: una nota sobre la recepción de Plinio en la literatura del Renacimiento". Teoría y análisis de los discursos literarios: estudios en homenaje al profesor Ricardo Senabre Sempere. Coord. Salvador CRespo Matellán. Salamanca: Universidad de Salamanca. Pp. 457-465.

2006. "Erasmo y la dignidad del hombre". La dignidad y la miseria del hombre en el pensamiento europeo: Actas del Congreso Internacional de Madrid, 20 a 22 de mayo de 2004. Ed. Guido M. CAPELLI. Roma: Salerno Editrice. Pp. 201-237. 
. 2003. "La tradición de miseria hominis y El Criticón". Baltasar Gracián IV Centenario (1601-2001): Actas II. Congreso Internacional "Baltasar Gracián en sus Obras", Zaragoza, 22-24 de noviembre de 2001. Eds. Aurora Egido, María del Carmen MARín Pina y Luis SÁnCHEZ LAílla. Zaragoza / Huesca: Institución Fernando el Católico, Instituto de Estudios Altoaragoneses / Gobierno de Aragón. Pp. 263-291.

Vilanova, Antonio. 1950. "El tema del gran teatro del mundo", Boletín de la Academia de las Buenas Letras de Barcelona, núm. XXIII. Barcelona: Reial Acadèmia de Bones Lletres. pp. 153-168.

VIVES, Juan Luis. 1998. Diálogos y otros escritos. Introducción, traducción y notas Juan Francisco AlcinA. Barcelona: Planeta.

YNDURÁIn, Domingo. 1997. "Prólogo" en El gran teatro del mundo de Pedro Calderón de la Barca. Ed. Domingo YnduRÁrn. Barcelona: Crítica. 